\title{
Increased risk of non-Hodgkin lymphoma and serum organochlorine concentrations among neighbors of a municipal solid waste incinerator
}

\author{
Jean-François Viel ${ }^{\mathrm{a}, *}$, Nathalie Floret ${ }^{\mathrm{a}}$, Eric Deconinck ${ }^{\mathrm{b}}$, Jean-François Focant ${ }^{\mathrm{c}}$, \\ Edwin De Pauw ${ }^{\mathrm{c}}$, Jean-Yves Cahn ${ }^{\mathrm{d}}$ \\ a CNRS no 6249 "Chrono-Environment", Faculty of Medicine, Besançon, France \\ b INSERM no 645 "Host graft interaction: cellular and genetic engineering in transplantation", Department of Hematology, University Hospital, Besançon, France \\ c Mass Spectrometry Laboratory-CART, University of Liège, Liège, Belgium \\ d CNRS no 5525 "Recombinant experimental therapy team", Department of Oncology and Hematology, University Hospital, Grenoble, France
}

\section{A R T I C L E I N F O}

\section{Article history:}

Received 21 September 2010

Accepted 18 November 2010

Available online 16 December 2010

\section{Keywords:}

Dioxin

Municipal solid waste incinerator

Non-Hodgkin lymphoma

Organochlorines

Polychlorinated biphenyls

\begin{abstract}
A B S T R A C T
Organochlorine chemicals may contribute to an increased risk of non-Hodgkin lymphoma (NHL) within nonoccupationally exposed populations. Among these chemicals, dioxins and furans were mainly released by municipal solid waste incinerators (MSWIs) until a recent past in France, a source of exposure that is of public concern. We investigated organochlorines and the risk of NHL among neighbors of a French MSWI with high levels of dioxin emissions (Besançon, France), using serum concentrations to assess exposure. The study area consisted of three electoral wards, containing or surrounding the MSWI. Pesticides, dioxins, furans, and polychlorinated biphenyls (PCBs) were measured in the serum of 34 newly diagnosed NHL cases (20032005) and 34 controls. Risks of NHL associated with each lipid-corrected serum concentration were estimated using exact logistic regression. The pesticides $\beta$-hexachlorocyclohexane (odds ratio $[\mathrm{OR}]=1.05,95 \%$ confidence interval $[\mathrm{Cl}]=1.00-1.12$, per $10 \mathrm{ng} / \mathrm{g}$ lipid) and $p, p^{\prime}$ dichloro-diphenyl-trichloroethane (DDT) $(\mathrm{OR}=1.20,95 \% \mathrm{CI}=1.01-1.45$, per $10 \mathrm{ng} / \mathrm{g}$ lipid) were associated with $\mathrm{NHL}$ risk. Evidence indicated an increased $\mathrm{NHL}$ risk associated with cumulative $\mathrm{WHO}_{1998}$-toxic equivalency factor (TEQ) concentrations (dioxins, $\mathrm{OR}=1.12,95 \% \mathrm{CI}=1.03-1.26$; furans, $\mathrm{OR}=1.16,95 \% \mathrm{CI}=1.03-1.35$; dioxin-like $\mathrm{PCBs}, \mathrm{OR}=1.04$, $95 \% \mathrm{CI}=1.00-1.07$; and total TEQ $\mathrm{OR}=1.04,95 \% \mathrm{CI}=1.01-1.05)$, as well as with non dioxin-like PCBs $(\mathrm{OR}=1.02,95 \% \mathrm{CI}=1.01-1.05$, per $10 \mathrm{ng} / \mathrm{g}$ lipid $)$. Most congener-specific associations were statistically significant. This study provides strong and consistent support for an association between serum cumulative $\mathrm{WHO}_{1998}$-TEQ concentrations, at levels experienced by people residing in the vicinity of a polluting MSWI, and risk of NHL.
\end{abstract}

(C) 2010 Elsevier Ltd. All rights reserved.

\section{Introduction}

The etiology of the most common types of non-Hodgkin's lymphoma (NHL) remains elusive, and the well established risk factors (immunodeficiency disorders, autoimmune diseases, some infectious agents in specific subtypes) explain only a small percentage

Abbreviations: CI, confidence interval; DDE, dichloro-diphenyl-dichloroethylene; DDT, $p, p^{\prime}$ dichloro-diphenyl-trichloroethane; EBV, Epstein-Barr virus; HCB, hexachlorobenzene; $\mathrm{HCCH}$, hexachlorocyclohexane; IARC, International Agency for Research on Cancer; I-TEQ international toxic equivalency factor; LOQ limit of quantification MSWI, municipal solid waste incinerator; NDL-PCB, non dioxin-like polychlorinated biphenyls; NHL, non-Hodgkin lymphoma; OR, odds ratio; $\mathrm{PCB}$, polychlorinated biphenyls; PCDD, polychlorinated dibenzo-p-dioxins; PCDF, polychlorinated dibenzofurans; TCDD, tetrachlorodibenzo-p-dioxin; WHO, World Health Organization.

* Corresponding author. CNRS no 6249 "Chrono-Environment", Faculty of Medicine, 2, place Saint Jacques, 25030 Besançon, France. Tel.: +33 381218 734; fax: +33 381 218735.

E-mail address: jean-francois.viel@univ-fcomte.fr (J.-F. Viel). of the NHL cases (Alexander et al., 2007). The epidemic of NHL observed during the second half of the 20th century has now started to level off in North America and Europe. This trend might be partly explained by a decrease in the widespread exposure to common chemicals (such as pesticides and persistent organic pollutants) following enforcement of regulations in the 1970s and 1980s (Hardell and Eriksson, 2003).

One dioxin congener $\left(2,3,7,8-\mathrm{T}_{4} \mathrm{CDD}\right.$ or $\left.\mathrm{TCDD}\right)$ and one furan congener $\left(2,3,4,7,8-\mathrm{P}_{5} \mathrm{CDF}\right)$ are considered carcinogenic to humans by the International Agency for Research on Cancer (IARC) for all cancers (Baan et al., 2009). For NHL specifically, increased incidence and mortality have been reported in several investigations conducted on cohorts of workers exposed to TCCD (Becher et al., 1996; Kogevinas et al., 1997; Hooiveld et al., 1998; Bodner et al., 2003), and on an exposed population following an accidental industrial release of TCDD in Seveso (Italy) (Consonni et al., 2008). However, few studies have examined the effects of environmental dioxin exposure. Emissions from municipal solid waste incinerators (MSWIs) are one of the major 
sources of dioxins and furans in France, and are therefore a source of exposure that is of public concern. Our team first detected a cluster of NHL in an area surrounding an MSWI with high levels of dioxin emissions (Besançon, France) (Viel et al., 2000). Subsequently, an increased risk (odds ratio $[\mathrm{OR}]=2.3,95 \%$ confidence interval $[\mathrm{CI}] 1.4$ to 3.8) of NHL was associated with residence under the plume of this MSWI (Floret et al., 2003). These findings have recently been replicated at the national level with a similar exposure assessment approach (Viel et al., 2008).

Polychlorinated biphenyls (PCBs) are considered probable human carcinogens by the IARC, with the exception of the recent classification of PCB 126 as carcinogenic to humans (Baan et al., 2009). Dioxinlike (DL) PCBs exhibit similar toxicologic properties as dioxins through their potential to bind to the arylhydrocarbon receptor, whereas non dioxin-like (NDL) PCBs elicit biological responses that are primarily mediated through other pathways such as immunosuppression (Safe, 1993). Several studies have suggested a role for PCBs in the development of NHL (Hardell et al., 1996; Rothman et al., 1997; Engel et al., 2007).

There has been also considerable interest in the question of whether exposure to pesticides causes NHL, with recent reviews highlighting pesticide exposure as one of the likely occupational risk factors for this cancer (Baris and Zahm, 2000; Fisher and Fisher, 2004).

The lipid-soluble nature of the different organochlorine classes results in similar bioaccumulation patterns. Owing to their prolonged half-lives, organochlorine levels in blood reflect cumulative exposure over time and can cause chronic toxicity after long-term exposure, even if the exposure dose is relatively low (Dich et al., 1997).

Our goal, therefore, was to investigate the association between risk of NHL and serum concentrations of organochlorines in the vicinity of a polluting MSWI (Besançon, France).

\section{Materials and Methods}

\subsection{Study area}

The MSWI of Besançon was put into service in 1971. Some legal guidelines for incinerator emissions have not been followed at this location. For example, in 1997, exhaust gases were not maintained at sufficient temperatures, allowing dioxins to be emitted. The first time that the dioxin concentration of an exhaust gas was ever measured (December 1997), it was found to be $16.3 \mathrm{ng} \mathrm{WHO}_{1998}$-toxic equivalency factor (TEQ) $/ \mathrm{m}^{3}$, whereas the European guide value is $0.1 \mathrm{ng} \mathrm{WHO}_{1998}-\mathrm{TEQ} / \mathrm{m}^{3}$.

The study area consisted of three electoral wards $(170,000$ inhabitants), containing or surrounding the MSWI. As a result, exposed people could live, work, do outdoor leisure activities, or eat locally produced food in the impact area of the MSWI's plume.

\subsection{Study population}

Cases included subjects with newly diagnosed NHL between January 1, 2003, and December 31, 2005, at the Department of Hematology of the University Hospital (the only tertiary referral hospital in the region) who were living in the study area. The completeness of case ascertainment was verified by linkages with computerized hospital discharge data. The total number of eligible cases was 53 (vs. a mean of 56 forecasted cases according to the local populations and rates in 2002). Of the eligible cases, three rapidly died, five could not participate due to poor health, eight refused, and 37 consented. Unfortunately, three blood samples could not be tested due to hepatitis B, hepatitis C, and suspected HTLV-1 seropositivities, leaving 34 cases for analysis.

Controls were randomly selected from the donor registry of the regional blood bank living in the study area according to a one-to-one matching procedure. Matching criteria were sex, age ( \pm 5 years), and date of blood draw ( \pm 1 year). Five eligible controls refused to participate, and each of them was replaced by another control of similar characteristics for matching variables. Thus the present study encompassed 34 cases and 34 controls.

\subsection{Biomarkers}

A fasting blood sample of $150 \mathrm{ml}$ was drawn from each participant. All blood was processed at the regional blood bank in the same laboratory. Serum was separated from clotted blood by centrifugation and frozen at $-80^{\circ} \mathrm{C}$ until analysis was conducted. The samples were shipped in one batch that consisted of mixed cases and controls to the CART Mass Spectrometry Laboratory, University of Liège, Belgium. Samples were identified only by a unique sample code and thus were blinded for case-control status.

We measured a wide spectrum of organochlorines including 10 pesticides or pesticide metabolites (hexachlorobenzene [HCB], $\beta$ - and $\gamma$-hexachlorocyclohexane $[\mathrm{HCCH}]$, oxychlordane, trans-nonachlor, cis-nonachlor, $p, p^{\prime}$-dichloro-diphenyl-dichloroethylene [DDE], o, $p^{\prime}$ dichloro-diphenyl-trichloroethane [DDT], p,p'-DDT, and mirex), the 17 2,3,7,8-substituted dioxins (PCDDs) and furans (PCDFs), 12 DLPCBs (non-ortho substituted-77, 81, 126, 169, and mono-ortho substituted-105, 114, 118, 123, 156, 157, 167, 189), and 6 NDLPCBs $(28,52,101,138,153,209)$. Pesticides were measured by gas chromatography coupled to electron-capture detection. PCDD/Fs and PCBs were measured by gas chromatography coupled to isotopedilution high-resolution mass spectrometry. The methods have been validated under International Organization for Standardization 17025 criteria. Instrument performance, multi-level quality control, and blank levels were monitored following Focant et al. (2006). For four pesticide analytes (trans-nonachlor, cis-nonachlor, $0, p^{\prime}$-DDT, and mirex), four PCDF congeners $\left(1,2,3,7,8-\mathrm{P}_{5} \mathrm{CDF}, 1,2,3,7,8,9-\mathrm{H}_{6} \mathrm{CDF}\right.$, $1,2,3,4,6,7,8-\mathrm{H}_{7} \mathrm{CDF}$, and $\left.1,2,3,4,7,8,9-\mathrm{H}_{7} \mathrm{CDF}\right)$, and three NDL-PCBs $(28,52,101)$, fewer than $50 \%$ of the samples had levels above the limit of quantification (LOQ). Following Engel et al. (2007), these compounds were not considered to minimize any distortion of exposure measurement due to high proportions of input values.

Total lipid concentration was calculated for each serum sample using enzymatic methods. Concentrations of PCDDs, PCDFs, and DLPCBs were expressed in pg $\mathrm{WHO}_{1998}$-TEQ per gram of lipids, while concentrations of pesticides and NDL-PCBs were expressed in ng per gram of lipids.

\subsection{Questionnaires}

Written informed consent was obtained from each participant before the interview. A single epidemiologist collected data through a face-to-face interview.

Socio-demographic and physiological factors included age, sex, tobacco status, education, occupational social class (I, managers, professionals, and self-employed workers; II, non-manual employees [higher grade]; III, non-manual employees [lower grade]; IV, skilled workers, non-skilled workers, and agricultural laborers), and length of residency in the study area since the incinerator installation. Body mass index (BMI) was calculated based on self-reported height and weight at the time of inclusion.

Participants were asked if they had ever worked in any of six industries previously defined to potentially expose workers to dioxins or other organochlorine compounds: metal, pulp and paper, incineration, petroleum, pesticide manufacturing, and textile industries.

Food intake was quantified by a simplified food frequency questionnaire focusing on the food vectors for animal lipids that are also the food vectors for organochlorines: meat (beef, pork, and sheep), poultry and eggs, fish (lean fish and fatty fish), shellfish, and dairy products (cheese and milk). 


\subsection{Statistical analysis}

Serum values below the LOQ were assigned half the LOQ. The Wilcoxon-Mann-Whitney test was used to compare mean serum lipid levels. Spearman rank correlations were calculated between lipid-adjusted organochlorine concentrations. OR and 95\% CI for the risk of NHL associated with each biomarker were estimated using exact logistic regression models. For the sake of clarity, the ORs associated with pesticides and NDL-PCBs were given for a 10-unit increase. All the above analyses were conducted using LogXact software (Cytel Inc., Cambridge, MA USA). All statistical tests were two-sided.

No subgroup analyses of the associations between organochlorines and NHL were performed for histological subtypes because of the small sample size.

\subsection{Ethics}

Ethical clearance for this study was granted by the Consulting Committee for the Treatment of Information in Medical Research (no. 02.16), the National Commission for the Confidentiality of Computerized Data (no. 902087), and the regional Consultative Committee for the Protection of Persons involved in Biomedical Research.

\section{Results}

The evaluated subtypes of NHL comprised the following: diffuse large B cell lymphoma $(n=11)$, marginal zone lymphoma $(n=9)$, follicular lymphoma $(n=3)$, small lymphocytic lymphoma/chronic lymphocytic leukemia $(n=3)$, mantle cell lymphoma $(n=3)$, peripheral $(n=2)$ and anaplastic $(n=2)$ T-cell lymphoma, and Burkitt's lymphoma $(n=1)$.

Although we attempted to enroll cases prior to the onset of chemotherapy, 10 patients underwent blood withdrawal after initiating chemotherapy (median time to blood draw from disease diagnosis: 71 days). The total serum lipid level did not differ between these cases (mean $=700 \mathrm{mg} / 100 \mathrm{~mL}$ ) and those who provided blood prior the onset of chemotherapy $(n=24$, mean $=626 \mathrm{mg} / 100 \mathrm{~mL})(p$-value $=0.93)$.

Selected characteristics of the study population are provided in Table 1. Cases and controls were well matched by sex and age. There was no appreciable difference in cigarette use, education, occupational social class, BMI, or length of residency in the study area. No participant had ever worked in a dioxin-generating industry. Regarding food frequencies, no difference was noted between cases and controls (Supplemental Table 1 ), and very few people reported occasional consumption of locally produced food.

Dioxin, furan, DL-PCB, and NDL-PCB concentrations showed strong correlation with each other, but low to moderate correlation with pesticides or pesticide metabolites (Table 2).

$\beta-\mathrm{HCCH}(\mathrm{OR}=1.05,95 \% \mathrm{CI}=1.00-1.12$, per $10 \mathrm{ng} / \mathrm{g}$ lipid $)$ and $p, p^{\prime}-\mathrm{DDT}$ $(\mathrm{OR}=1.20,95 \% \mathrm{Cl}=1.01-1.45$, per $10 \mathrm{ng} / \mathrm{g}$ lipid) were positively linked with $\mathrm{NHL}$ risk (Table 3). There were no other significant or noteworthy findings for the organochlorine pesticides or pesticide metabolites.

There was strong evidence of increased NHL risk associated with cumulative $\mathrm{WHO}_{1998}$-TEQ concentrations: PCDDs, $\mathrm{OR}=1.12,95 \% \mathrm{CI}=1.03-1.26$; PCDFs, $\mathrm{OR}=1.16,95 \% \mathrm{CI}=1.03-1.35$; $\mathrm{DL}-\mathrm{PCBs}, \mathrm{OR}=1.04,95 \% \mathrm{CI}=1.00-1.07$; and total TEQ $\mathrm{OR}=1.04,95 \% \mathrm{CI}=1.01-1.05$ (Table 4). The risk associated with NDL-PCBs was also significant ( $\mathrm{OR}=1.02,95 \% \mathrm{CI}=1.01-1.05$, per $10 \mathrm{ng} / \mathrm{g}$ lipid). To explore potential confounding, we included in turn, BMI, one of the two pesticides that were significantly associated with NHL ( $\beta-\mathrm{HCCH}$, and p, $p^{\prime}$-DDT), and cumulative NDL-PCBs in the models. The ORs did not substantially change when adjusting for BMI or pesticides, but were more or less attenuated by inclusion of NDL-PCBs (Supplemental Table 2).

Congener-specific results are reported in the Supplemental Table 3 for PCDDs and PCDFs, and the Supplemental Table 4 for PCBs. Each of the dioxin congeners was significantly associated with increased NHL risk ( $p$-values ranging from 0.006 to 0.05 ). Of the furan congeners, $1,2,3,4,7,8-\mathrm{H}_{6} \mathrm{CDF}$ was most strongly associated with NHL risk ( $p$-value $<0.001$ ). Risks associated with PCB congeners were all statistically significant, with the exceptions of PCB 77 and PCB 114.

\section{Discussion}

This study is the first report of an association between cumulative serum $\mathrm{WHO}_{1998}$-TEQ concentrations and risk of $\mathrm{NHL}$, at levels experienced by the general population in the vicinity of an MSWI. Our results also contribute to the body of evidence indicating that exposure to NDL-PCBs increases the risk of NHL.
Table 1

Selected characteristics of non-Hodgkin lymphoma cases $($ No $=34)$ and controls $(\mathrm{No}=34)$.

\begin{tabular}{lcc}
\hline Variable & Cases No (\%) & Controls No (\%) \\
\hline Gender & & \\
male & $15(44.1)$ & $15(44.1)$ \\
female & $19(55.9)$ & $19(55.9)$ \\
Age, y & & \\
$\quad<55$ & $12(35.3)$ & $12(35.3)$ \\
$55-63$ & $14(41.2)$ & $14(41.2)$ \\
$\geq 64$ & $8(23.5)$ & $8(23.5)$ \\
Cigarette use & & $5(14.7)$ \\
current & $5(14.7)$ & $14(41.2)$ \\
former & $12(35.3)$ & $15(44.1)$ \\
never & $17(50.0)$ & $22(64.7)$ \\
Education, y & & $12(35.3)$ \\
$<12$ & $22(64.7)$ & $8(23.5)$ \\
$\geq 12$ & $12(35.3)$ & $4(11.8)$ \\
Occupational social class & $11(32.4)$ & $14(41.2)$ \\
I & $2(5.9)$ & $8(23.5)$ \\
II & $10(29.3)$ & $1(2.9)$ \\
III & $11(32.4)$ & $25(73.5)$ \\
IV & $1(2.9)$ & $8(23.5)$ \\
Body mass index & $20(58.8)$ & $0(0.0)$ \\
$<18.5$ & $9(26.5)$ & $19(55.9)$ \\
$18.5-24.9$ & $4(11.8)$ & \\
$25-29.9$ & $20(58.8)$ & $(44.1)$ \\
$\geq 30$ & $14(41.2)$ & \\
Length of residency, y & & \\
$<20$ & & \\
$\geq 20$ & & \\
\hline
\end{tabular}

The major strength of this study is represented by the exposure assessment method which does not rely on participant recall and reflects short-to-long-term exposure. Fasting samples avoided methodological challenges with regard to lipids when using nonfasting blood specimens to estimate health risk (Schisterman et al., 2005). The serum sample volume allowed for the measurement of a broad range of organochlorines and the detection of compounds at low concentration. Other strengths of our study include the demographic matching of cases and controls, and the detailed information available about the subjects at the time of inclusion, such as lifestyle factors, occupation, and diet. However, no information was available on any temporal changes in body weight prior to disease diagnostic that could have influenced serum organochlorine concentrations among cases.

The moderate size of the study (which could not be controlled because of the nature of the study design) has not limited the statistical power of the analysis to identify significant findings but restricted multivariate adjustments, and did not allow for analysis by NHL subtype.

Although control subjects were recruited among blood bank donors, they can be considered broadly representative of the general population at least for two reasons. First, there was a balanced distribution of demographic characteristics (including BMI) among cases and controls, which cannot, therefore, bias the observed associations. Second, the cumulative serum PCDD/F WHO ${ }_{1998}$-TEQ concentrations among controls were similar to those measured among randomly selected people in the vicinity of eight other French MSWIs during the corresponding time period (Table 5) (Frery et al., 2009). In contrast, the observed increase of the DL-PCB WHO ${ }_{1998}$-TEQ concentrations suggests that a past exposure of the study area to PCBs may have occurred, possibly reflecting the environmental impact of the local MSWI.

The main limitation of this study is that eight cases with rapid death or poor prognosis were not included, as it was considered unethical to add to these patients' burden by drawing a $150-\mathrm{ml}$ blood sample. Our estimated increased risks from exposure to organochlorine compounds may not be applicable to all patients with NHL. 
Table 2

Spearman rank correlations between lipid-adjusted organochlorine concentrations.

\begin{tabular}{|c|c|c|c|c|c|c|c|c|c|c|}
\hline & $\mathrm{HCB}$ & $\beta-\mathrm{HCCH}$ & $\gamma$-HCCH & Oxychlordane & $p, p^{\prime}-\mathrm{DDE}$ & $p, p^{\prime}$-DDT & $\Sigma$ PCDD & $\Sigma$ PCDF & $\Sigma$ DL-PCB & $\Sigma$ NDL-PCB \\
\hline $\mathrm{HCB}$ & 1.00 & & & & & & & & & \\
\hline$\beta-\mathrm{HCCH}$ & 0.73 & 1.00 & & & & & & & & \\
\hline$\gamma-\mathrm{HCCH}$ & 0.55 & 0.51 & 1.00 & & & & & & & \\
\hline Oxychlordane & 0.61 & 0.30 & 0.47 & 1.00 & & & & & & \\
\hline$p, p^{\prime}-\mathrm{DDE}$ & 0.65 & 0.61 & 0.50 & 0.36 & 1.00 & & & & & \\
\hline$p, p^{\prime}-\mathrm{DDT}$ & 0.60 & 0.54 & 0.47 & 0.43 & 0.54 & 1.00 & & & & \\
\hline$\Sigma$ PCDD & 0.64 & 0.78 & 0.34 & 0.11 & 0.55 & 0.50 & 1.00 & & & \\
\hline$\Sigma$ PCDF & 0.67 & 0.74 & 0.34 & 0.18 & 0.55 & 0.52 & 0.92 & 1.00 & & \\
\hline$\Sigma$ DL-PCB & 0.59 & 0.78 & 0.31 & 0.05 & 0.54 & 0.51 & 0.89 & 0.87 & 1.00 & \\
\hline$\Sigma$ NDL-PCB & 0.57 & 0.67 & 0.34 & 0.09 & 0.62 & 0.61 & 0.80 & 0.79 & 0.91 & 1.00 \\
\hline
\end{tabular}

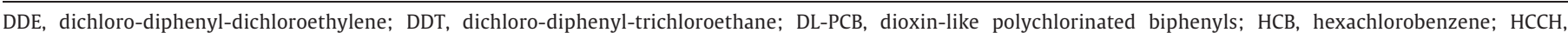
hexachlorocyclohexane; NDL-PCB, non dioxin-like polychlorinated biphenyls; PCDD, polychlorinated dibenzo-p-dioxins; PCDF, polychlorinated dibenzofurans.

One further limitation, shared with most prior studies on this topic, is the substantial correlation between dioxins, furans, and PCBs, making it difficult to tease apart which of these organochlorine classes are the true risk factors. We found evidence of some confounding by NDL-PCBs, although the risk of NHL associated with TEQ concentrations remained elevated. Epstein-Barr virus (EBV) serology was not performed because an interaction between EBV and organochlorines (Rothman et al., 1997; Hardell et al., 2001; Hardell et al., 2009) would not have been apparent, due to the limited number of participants.

Interference by the disease process and/or chemotherapy among NHL patients must be mentioned because blood withdrawal was performed after initiating chemotherapy for $29 \%$ of the cases. This interference should not have distorted our results for the following reasons. First, NHL treatment might depress, and not increase, organochlorine levels (Baris et al., 2000), and would (if ever) bias the ORs towards the null. Second, no substantial differences in the OR point estimates were seen after limiting the analyses to the 24 cases who underwent blood withdrawal before initiating chemotherapy (results not shown). Third, differential weight loss that could release stored organochlorines into the blood stream and induce an increase in organochlorine levels is not to be considered a factor as lipid levels did not differ between untreated and treated cases (being even slightly higher among treated patients). Fourth, the median interval between treatment and blood draw was rather short among the 10 concerned cases ( 71 days).

Very few studies have evaluated exposure to organochlorines in serum or plasma in relation to NHL within the general population. We found an increased risk of NHL with serum $\beta-\mathrm{HCCH}$ concentrations, in agreement with Spinelli et al. (2007). However, three other casecontrol studies did not observe such an association (De Roos et al., 2005; Cantor et al., 2003; Cocco et al., 2008). Our significant findings for $p, p^{\prime}$-DDT concentrations is contradictory to two other case-control studies that found no association with NHL (De Roos et al., 2005; Cantor et al., 2003; Bertrand et al., 2010).

Table 3

Odds ratios for the risk of non-Hodgkin lymphoma in relation to lipid-corrected serum concentrations of organochlorine pesticides.

\begin{tabular}{lclll}
\hline $\begin{array}{l}\text { Pesticide } \\
\text { (ng/g lipid) }\end{array}$ & $\begin{array}{l}\text { Cases } \\
\text { (mean) }\end{array}$ & $\begin{array}{l}\text { Controls } \\
\text { (mean) }\end{array}$ & OR $(95 \% \text { CI })^{\mathrm{a}}$ & -value \\
\hline HCB & 50.71 & 37.35 & $1.10(0.97-1.28)$ & 0.16 \\
$\beta$-HCCH & 98.61 & 48.08 & $1.05(1.00-1.12)$ & 0.05 \\
$\gamma$-HCCH & 24.89 & 17.77 & $1.16(0.93-1.49)$ & 0.20 \\
Oxychlordane & 44.67 & 45.68 & $0.99(0.88-1.13)$ & 0.91 \\
$p, p^{\prime}$-DDE & 153.10 & 89.49 & $1.03(0.99-1.08)$ & 0.07 \\
$p, p^{\prime}$-DDT & 36.83 & 18.87 & $1.20(1.01-1.45)$ & 0.03 \\
\hline
\end{tabular}

DDE, dichloro-diphenyl-dichloroethylene; DDT, dichloro-diphenyl-trichloroethane; $\mathrm{HCB}$, hexachlorobenzene; $\mathrm{HCCH}$, hexachlorocyclohexane.

a per $10 \mathrm{ng} / \mathrm{g}$ lipid.
To our knowledge, only one other study has addressed the issue of PCDD/F levels and NHL risk within a non-occupationally exposed population. In line with our results, De Roos et al. (2005) showed that plasma levels of total PCDFs, several individual PCDF congeners, and cumulative $\mathrm{WHO}_{1998}$-TEQ concentrations were positively associated with NHL risk.

Concerning PCBs, our findings are consistent with previously reported studies. Rothman et al. (1997) showed that total PCB levels measured in serum were strongly associated with increased risk of NHL in a nested case-control study. Engel et al. (2007) found exposure-response trends for several congeners $(118,138$, and 153) across three cohorts. Hardell et al. (2001) reported an increased risk of NHL incidence for the group of immunotoxic PCB congeners. De Roos et al. (2005) found exposure-response trends for PCB 156, РCB 180, and PCB 194 levels, Spinelli et al. (2007) for DL-PCBs (total, 118, 156) and NDL-PCBs (total, 99, 138, 153, 170, 180, 187), and Bertrand et al. (2010) for the sum of 51 PCBs and the group of immunotoxic congeners. Hardell et al. (2009) found an association of borderline significance between total PCBs and NHL risk. Inconsistent with our findings, Cocco et al. (2008) did not find evidence of an association between NHL risk and levels of PCBs.

In conclusion, we report a strong and consistent association between NHL risk and serum levels of PCDDS, PCDFs, and DL-PCBs, among people residing in the vicinity of an MSWI with high dioxin emission levels (Besançon, France). These pollutants could involve the development of NHL through a chromosomal translocation $t(14 ; 18)$ pathway. Two case-control studies found that the association between pesticide exposure and risk of NHL was limited to $t(14 ; 18)$ positive NHL cases (Schroeder et al., 2001; Chiu et al., 2006), suggesting that exposure to organochlorines could cause expansion of $\mathrm{t}(14 ; 18)$-positive clones. These findings are supported by two

Table 4

Odds ratios for the risk of non-Hodgkin lymphoma in relation to lipid-corrected cumulative serum concentrations of dioxins, furans, dioxin-like polychlorinated biphenyls, and non dioxin-like polychlorinated biphenyls.

\begin{tabular}{|c|c|c|c|c|}
\hline Cumulative concentrations & $\begin{array}{l}\text { Cases } \\
\text { (mean) }\end{array}$ & $\begin{array}{l}\text { Controls } \\
\text { (mean) }\end{array}$ & OR $(95 \% \mathrm{CI})$ & $p$-value \\
\hline$\Sigma \mathrm{PCDD}^{\mathrm{a}}$ & 13.39 & 8.73 & $1.12(1.03-1.26)$ & $<0.01$ \\
\hline$\Sigma \mathrm{PCDF}^{\mathrm{a}}$ & 9.44 & 6.27 & $1.16(1.03-1.35)$ & 0.01 \\
\hline$\Sigma$ DL-PCB ${ }^{\mathrm{a}}$ & 33.13 & 20.10 & $1.04(1.00-1.07)$ & 0.02 \\
\hline$\Sigma(P C D D+P C D F+D L-P C B)^{a}$ & 55.96 & 35.10 & $1.04(1.01-1.05)$ & 0.01 \\
\hline$\Sigma$ NDL-PCB ${ }^{\mathrm{b}}$ & 541.30 & 335.5 & $1.02^{\mathrm{c}}(1.01-1.05)$ & 0.01 \\
\hline
\end{tabular}

DL-PCB, dioxin-like polychlorinated biphenyls; NDL-PCB, non dioxin-like polychlorinated biphenyls; PCDD, polychlorinated dibenzo-p-dioxins; PCDF, polychlorinated dibenzofurans; TEQ toxic equivalency factor; WHO, World Health Organization.

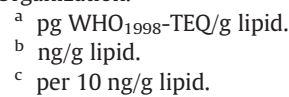


Table 5

Cumulative serum organochlorine concentrations in non-occupationally exposed populations living near French municipal solid waste incinerators.

\begin{tabular}{lcc}
\hline Cumulative concentrations & This study (2003-2005) & France $(2005)^{\mathrm{a}}$ \\
\hline L PCDD $^{\mathrm{b}}$ & 8.73 & 8.4 \\
$\Sigma$ PCDF $^{\mathrm{b}}$ & 6.27 & 6.7 \\
$\Sigma \mathrm{DL}^{\mathrm{P} C B^{\mathrm{b}}}$ & 20.10 & 15.8 \\
$\Sigma(\mathrm{PCDD}+\mathrm{PCDF}+\mathrm{DL}-\mathrm{PCB})^{\mathrm{b}}$ & 35.10 & 30.9 \\
N NDL-PCB $^{\mathrm{C}}$ & 335.5 & 387.0 \\
\hline
\end{tabular}

DL-PCB, dioxin-like polychlorinated biphenyls; NDL-PCB, non dioxin-like polychlorinated biphenyls; PCDD, polychlorinated dibenzo-p-dioxins; PCDF, polychlorinated dibenzofurans; TEQ toxic equivalency factor; WHO, World Health Organization.

a Frery et al., 2009.

b $\mathrm{pg} \mathrm{WHO}_{1998}-\mathrm{TEQ} / \mathrm{g}$ lipid.

c ng/g lipid.

recent biological studies. Baccarelli et al. (2006) found that TCDD exposure was associated with increased numbers of $\mathrm{t}(14 ; 18)$-positive circulating lymphocytes in healthy individuals from Seveso. Agopian et al. (2009) demonstrated that expanded $t(14 ; 18)$-positive clones provide a molecular connection between agricultural pesticide exposure, $\mathrm{t}(14 ; 18)$ frequency in blood, and clonal expansion.

However, assuming that the association found in our study reflects a true causal relationship, it is unclear which source and route of exposure lead to the pathogenesis of NHL in the study area. Although the amounts of organochlorines emitted by the local MSWI into the environment before compliance with the stringent emission standards cannot be readily estimated, some further arguments point to the potential responsibility of the MSWI: a high dioxin emission level in 1997, no adjacent industrial sources of exposure, and high serum PCB levels among controls.

\section{Acknowledgments}

We thank the medical staff at the University Hospital and the Regional Blood Bank (particularly Fabienne Pouthier), Besançon, France; and the staff of the Laboratory of Animal Ecology and Ecotoxicology, CART, University of Liège, Belgium. This work was supported by the French Ministry of Health (grant 2001-1485).

\section{Appendix A. Supplementary data}

Supplementary data to this article can be found online at doi:10.1016/j.envint.2010.11.009.

\section{References}

Agopian J, Navarro JM, Gac AC, Lecluse Y, Briand M, Grenot P, et al. Agricultural pesticide exposure and the molecular connection to lymphomagenesis. J Exp Med 2009;206: 1473-83.

Alexander DD, Mink PJ, Adami HO, Chang ET, Cole P, Mandel JS, et al. The non-Hodgkin lymphomas: A review of the epidemiologic literature. Int J Cancer 2007;120(Suppl 12):1-39.

Baan R, Grosse Y, Strai K, Secretan S, El Ghissassi F, Bouvard V, et al. A review of human carcinogens-Part F: Chemical agents and related occupations. Lancet Oncol 2009; 10:1143-4.

Baccarelli A, Hirt C, Pesatori AC, Consonni D, Patterson Jr DG, Bertazzi PA, et al. T(14;18) translocations in lymphocytes of healthy dioxin-exposed individuals from Seveso, Italy. Carcinogenesis 2006;27:2001-7.

Baris D, Kwak LW, Rothman N, Wilson W, Manns A, Tarone RE, et al. Blood levels of organochlorines before and after chemotherapy among non-Hodgkin's lymphoma patients. Cancer Epidemiol Biomark Prev 2000;9:193-7.

Baris D, Zahm SH. Epidemiology of lymphomas. Curr Opin Oncol 2000;12:383-94.
Becher H, Flesch-Janys D, Kauppinen T, Kogevinas M, Steindorf K, Manz A, et al. Cancer mortality in German male workers exposed to phenoxy herbicides and dioxins. Cancer Causes Control 1996;17:312-21.

Bertrand KA, Spiegelman D, Aster JC, Altshul LM, Korrick SA, Rodig SJ, et al. Plasma organochlorine levels and risk of non-Hodgkin lymphoma in a cohort of men. Epidemiology 2010;21:172-80.

Bodner KM, Collins JJ, Bloemen LJ, Carson M. Cancer risk for chemical workers exposed to 2,3,7,8-tetrachlorodibenzo-p-dioxin. Occup Environ Med 2003;60:672-5.

Cantor KP, Strickland PT, Brock JW, Bush D, Helzlsouer K, Needham LL, et al. Risk of nonHodgkin's lymphoma and prediagnostic serum organochlorines: $\beta$-hexachlorocyclohexane, chlordane/heptachlor-related compounds, dieldrin, and hexachlorobenzene. Environ Health Perspect 2003;111:179-83.

Chiu BC, Dave BJ, Blair A, Gapstur SM, Zahm SH, Weisenburger DD. Agricultural pesticide use and risk of $t(14 ; 18)$-defined subtypes of non-Hodgkin lymphoma. Blood 2006;108:1363-9.

Cocco P, Brennan P, Ibba A, de Sanjosé Llongueras S, Maynadié M, Nieters A, et al. Plasma polychlorobiphenyl and organochlorine pesticide level and risk of major lymphoma subtypes. Occup Environ Med 2008;65:132-40.

Consonni D, Pesatori AC, Zocchetti C, Sindaco R, D'Oro LC, Rubagotti M, et al. Mortality in a population exposed to dioxin after the Seveso, Italy, accident in 1976: 25 years of follow-up. Am J Epidemiol 2008;167:847-58.

De Roos AJ, Hartge P, Lubin JH, Colt JS, Davis S, Cerhan JR, et al. Persistent organochlorine chemicals in plasma and the risk of non-Hodgkin's lymphoma. Cancer Res 2005;65: 11214-26.

Dich J, Zahm SH, Hanberg A, Adami HO. Pesticides and cancer. Cancer Causes Control 1997;8:420-43.

Engel LS, Laden F, Andersen A, Strickland PT, Blair A, Needham LL, et al. Polychlorinated biphenyl levels in peripheral blood and non-Hodgkin's lymphoma: a report from three cohorts. Cancer Res 2007;67:5545-52.

Fisher SG, Fisher RI. The epidemiology of non-Hodgkin's lymphoma. Oncogene 2004;23:6524-34.

Floret N, Mauny F, Challier B, Arveux P, Cahn JY, Viel JF. Dioxin emissions from a solid waste incinerator and risk of non-Hodgkin lymphoma. Epidemiology 2003;14:392-8.

Focant JF, Eppe G, Massart AC, Scholl G, Pirard C, De Pauw E. High-throughput biomonitoring of dioxins and polychlorinated biphenyls at the sub-picogram level in human serum. J Chromatogr A 2006;1130:97-107.

Frery N, Zeghnoun A, Sarter H, Falq G, Pascal M, Bérat B, et al. National study on serum dioxins and PCB levels among people living around municipal solid waste incinerators. Saint Maurice, France: French Institute for Public Health Surveillance; 2009. http://www.invs.sante.fr/publications/2009/impregnation_dioxines_uiom/ impregnation_dioxines_uiom.pdf [accessed 21 September 2010].

Hardell L, van Bavel B, Lindström G, Fredriksson M, Hagberg H, Liljegren G, et al. Higher concentrations of specific polychlorinated biphenyl congeners in adipose tissue from non-Hodgkin's lymphoma patients compared with controls without a malignant disease. Int J Oncol 1996;9:603-8.

Hardell K, Carlberg M, Hardell L, Björnfoth H, Ericson Jogsten I, Eriksson M, et al. Concentrations of organohalogen compounds and titres of antibodies to Epstein-Barr virus antigens and the risk for non-Hodgkin lymphoma. Oncol Rep 2009;21:1567-76.

Hardell L, Eriksson M. Is the decline of the increasing incidence of non-Hodgkin lymphoma in Sweden and other countries a result of cancer preventive measures? Environ Health Perspect 2003;111:1704-6.

Hardell L, Eriksson M, Lindström G, van Bavel B, Linde A, Carlberg M, et al. Case control study on concentrations of organohalogen compounds and titers of antibodies to Epstein-Barr virus antigens in the etiology of non-Hodgkin lymphoma. Leuk Lymphoma 2001;42:619-29.

Hooiveld M, Heederik DJ, Kogevinas M, Boffetta P, Needham LL, Patterson Jr DG, et al. Second follow-up of a Dutch cohort occupationally exposed to phenoxy herbicides, chlorophenols, and contaminants. Am J Epidemiol 1998;147:891-901.

Kogevinas M, Becher H, Benn T, Bertazzi PA, Boffetta P, Bueno-de-Mesquita HB, et al. Cancer mortality in workers exposed to chlorophenoxy herbicides, chlorophenols and dioxins: An expanded and updated international cohort study. Am J Epidemiol 1997; $145: 1061-75$

Rothman N, Cantor KP, Blair A, Bush D, Brock JW, Helzlsouer K, et al. A nested case control study of non-Hodgkin lymphoma and serum organochlorine residues. Lancet 1997;350:240-4.

Safe S. Toxicology, structure-function relationship, and human and environmental health impacts of polychlorinated biphenyls: Progress and problems. Environ Health Perspect 1993;100:259-68.

Schisterman EF, Whitcomb BW, Louis GM, Louis TA. Lipid adjustment in the analysis of environmental contaminants and human health risks. Environ Health Perspect 2005; 113:853-7.

Schroeder JC, Olshan AF, Baric R, Dent GA, Weinberg CR, Yount B, et al. Agricultural risk factors for $\mathrm{t}(14 ; 18)$ subtypes of non-Hodgkin's lymphoma. Epidemiology 2001;12: $701-9$.

Spinelli JJ, Ng CH, Weber JP. Organochlorines and risk of non-Hodgkin lymphoma. Int J Cancer 2007;121:2767-75.

Viel JF, Arveux P, Baverel J, Cahn JY. Soft-tissue sarcoma and non-Hodgkin's lymphoma clusters around a municipal solid waste incinerator with high dioxin emission levels. Am J Epidemiol 2000;152:13-9.

Viel JF, Daniau C, Goria S, Fabre P, de Crouy-Chanel P, Sauleau EA, et al. Risk for non Hodgkin's lymphoma in the vicinity of French municipal solid waste incinerators. Environ Health 2008;7:51. 